\title{
QUALIDADE DO CARVÃO VEGETAL VISANDO USO DOMÉSTICO
}

\section{BIOENG $\quad$ D. P. Garcia ${ }^{1 *}$, C.R. Rodrigues ${ }^{1}$, E. A. Dal Bem¹, J. P. Ferreira ${ }^{2}$}

${ }^{1}$ FAIT - Faculdade de Ciências Sociais e Agrárias, Departamento de Ciências Florestais, Itapeva, SP, Brasil

${ }^{2}$ FAIT - Faculdade de Ciências Sociais e Agrárias, Departamento de Ciências Agronômicas, Itapeva, SP, Brasil

Article history: Received 23 January 2017; Received in revised form 28 February 2017; Accepted 03 March 2017; Available online 27 March 2017.

\section{RESUMO}

O Brasil é o maior produtor e consumidor mundial de carvão vegetal. Só as indústrias siderúrgicas consomem cerca de $70 \%$ da produção nacional. As aplicações residenciais e comerciais utilizam 0,14\% dessa produção, representando consumo de 871 mil t em 2015. Embora haja muitos artigos discorrendo sobre o carvão vegetal, são poucos os que tratam da qualidade, sobretudo comparando com os padrões estabelecidos na Resolução no 40, da Secretaria de Abastecimento e Agricultura. Desta forma, esse artigo faz uma avaliação do carvão vegetal, comparando-os com este padrão de qualidade. Com base em cinco amostras comerciais, adotou-se a umidade, cinzas, materiais voláteis, carbono fixo, poder calorífico superior e rótulos das embalagens como variáveis características de qualidade. Assim, dentre os 25 parâmetros avaliados, 36\% não foram atendidos. Concluindo que as amostras apresentaram baixa qualidade para uso doméstico e as empresas não cumprem exigências mínimas de qualidade para o produto.

Palavras-chave: análise imediata, poder calorífico, biocombustível, biomassa.

\section{CHARCOAL QUALITY FOR DOMESTIC USE}

\begin{abstract}
Brazil is the world's largest producer and consumer of charcoal. Only the steel industries consume about $70 \%$ of the national production. Residential and commercial applications use $0.14 \%$ of this production, representing a consumption of $871,000 \mathrm{t}$ in 2015 . Although there are many articles on charcoal, there are few that deal with quality, especially in comparison with the standards established in Resolution 40, of the Secretariat of Supply and Agriculture. In this way, this article makes an evaluation of charcoal, comparing them with this quality standard. Based on five commercial samples, moisture, ash, volatile materials, fixed carbon, higher calorific value and packaging labels were adopted as characteristic variables of quality. Thus, among the 25 parameters evaluated, 36\% were not attended. Concluding that the samples presented low quality for domestic use and companies do not meet minimum quality requirements for the product.
\end{abstract}

Keywords: immediate analysis, calorific value, biofuel, biomass.

* pelletsdemadeira@gmail.com 


\section{INTRODUÇÃO}

A Conferência do Clima (COP21), que ocorreu em dezembro de 2015 na França, sinalizou que haverá uma transição para a energia de baixo carbono no século XXI. Os combustíveis fósseis e seus derivados (gás natural, por exemplo), por conta de suas emissões poluentes responsáveis pelo aquecimento global, serão substituídos por energia limpa (JUNG et al., 2015).

A biomassa florestal é um recurso renovável e menos poluente, porque é considerada neutro em carbono, ou seja, todo $\mathrm{o} \quad \mathrm{CO}_{2}$ liberado pela madeira na queima é recuperado no crescimento da árvore. $O$ carvão vegetal tem essas características de recurso energético de baixo carbono (SOUZA et al., 2016).

O Brasil é o maior produtor e, ao mesmo tempo, o maior consumidor mundial de carvão vegetal. Em 2015, foram consumidos cerca de 6 milhões de toneladas deste insumo, sendo que $84 \%$ desse volume foram destinados ao setor industrial, sobretudo para as indústrias siderúrgicas e metalúrgicas, no estado de Minas Gerais, que sozinhas consumiram mais de $70 \%$ da produção nacional (BRASIL, 2016).

O carvão vegetal também é utilizado para outros fins, tais como: cocção de alimentos, lareiras, purificação de água e bebidas, indústria farmacêutica, filtros de máscaras contra gases dentre outros (SOUZA et al., 2016). Inclusive, para uso doméstico e pequenas aplicações comerciais (restaurantes), o país consumiu cerca de 871 mil toneladas, que representa $0,14 \%$ da produção total do país (BRASIL, 2016).

JÚNIOR et al. (2015) destacam que o carvão vegetal para ser considerado de boa qualidade para uso doméstico deve reunir características como alta densidade, alto teor de carbono fixo, alto poder

\section{MATERIAL E MÉTODOS}

Utilizou-se cinco amostras de carvão vegetal adquiridas em estabelecimentos calorífico, baixo teor de umidade, baixo teor de materiais voláteis e baixo teor de cinzas.

Já SOUZA et al. (2016) relatam que a qualidade do produto para o consumidor final é um dos principais aspectos para sua aceitação no mercado. Os autores associam o bom carvão vegetal à espécie da madeira, tamanho das peças que serviram como matéria-prima e o método de carbonização.

No entanto, LANA et al. (2016) destaca que a avaliação realizada por meio da análise imediata fornece os principais indicadores de qualidade do carvão vegetal, com o teor de materiais voláteis determinando a facilidade de ignição, a estabilidade da chama e a velocidade de combustão; o carbono fixo, definindo a quantidade de carbono presente no carvão e o teor de cinzas, indicando a massa residual de sólidos inorgânicos existente no combustível vegetal.

No Estado de São Paulo, o controle de qualidade do carvão vegetal para uso doméstico é realizado por meio da Resolução no 40 SAA/2015, da Secretaria de Agricultura e Abastecimento do Estado de São Paulo, que define padrões mínimos de qualidade para o carvão vegetal chamado de "Qualidade São Paulo", incluindo indicadores para teor de umidade $(<5 \%)$, teor de carbono fixo $(>73 \%)$, teor de materiais voláteis $(<25,5 \%)$, teor de cinzas $(<1,5 \%)$, bem como questões inerentes às embalagens do produto $\mathrm{e}$ informações básicas aos consumidores (SÃO PAULO, 2015).

Embora haja essa normativa de qualidade, não há garantias de seu efetivo cumprimento. Diante desse cenário, este trabalho teve como objetivo avaliar a qualidade do carvão vegetal, para uso doméstico, comercializado na Região de Itapeva/SP.

comerciais, na Região de Itapeva/SP, no período de janeiro a março de 2016. A 
localidade escolhida é conhecida como $16^{\mathrm{a}}$ Região Administrativa do Estado de São Paulo, e tem economia influenciada por áreas de reflorestamento e indústrias madeireiras. Como as amostras referem-se a produtos comerciais (Tabela 1), foram identificadas apenas por um número, para evitar a promoção positiva ou negativa das marcas. Elas encontravam-se em suas embalagens comerciais de venda. As empresas informam nas embalagens que os produtos foram produzidos com madeira de reflorestamento, mas não detalham a espécie e a idade dos materiais utilizados para a fabricação do carvão vegetal.

Tabela 1. Informações iniciais sobre as amostras comerciais de carvão vegetal.

\begin{tabular}{clccc}
\hline Amostra & Gênero/Espécie & $\begin{array}{c}\text { Embalagem } \\
(\mathbf{k g})\end{array}$ & $\begin{array}{c}\text { Cidade de } \\
\text { origem }\end{array}$ & $\begin{array}{c}\text { Material da } \\
\text { embalagem }\end{array}$ \\
\hline 1 & Eucalyptus $\mathrm{spp}$. & 2,5 & Itapeva/SP & Papel \\
2 & Eucalyptus $\mathrm{spp}$. & 3,0 & Itapeva/SP & Papel \\
3 & Eucalyptus $\mathrm{spp}$. & 2,5 & Itapeva/SP & Papel \\
4 & Eucalyptus $\mathrm{spp}$. & 2,5 & Itapeva/SP & Papel \\
5 & Eucalyptus $\mathrm{spp}$. & 5,0 & Buri/ SP & Papel \\
\hline
\end{tabular}

As amostras do carvão vegetal foram previamente secas a $103 \pm 2{ }^{\circ} \mathrm{C}$ durante 24 horas, até obtenção de massa constante, depois resfriadas num secador de sílica e pesadas com balança analítica de precisão $(0,001 \mathrm{~g})$. Para o poder calorífico superior utilizou-se uma bomba calorimétrica isotérmica marca Ika Works modelo C5000. Tanto para a análise química imediata do carvão vegetal quanto para o poder calorífico superior, as amostras foram moídas e peneiradas a uma granulometria de aproximadamente 0,2 $\mathrm{mm}$, conforme normas brasileiras relatadas na Tabela 2.

Para a análise imediata foram coletadas amostras simples de cada um dos carvões vegetais para análises em triplicata. O material volátil é emitido durante o aquecimento do carvão vegetal que é constituído de moléculas de $\mathrm{CO}, \mathrm{CO}_{2}$ e hidrocarbonetos. A quantidade de carbono que não volatiza recebe o nome de carbono fixo. Assim, o teor de materiais voláteis (MV) foi determinado pelo aquecimento do material a $900 \pm 10^{\circ} \mathrm{C}$, em forno mufla, com as amostras tampadas em cadinhos. Elas foram inicialmente levadas à porta da mufla por 3 minutos, para aclimatação, e ficaram por mais 7 minutos, no interior do equipamento, com a porta fechada. $\mathrm{O}$ teor de carbono fixo foi calculado pela soma dos teores de materiais voláteis e cinzas, subtraído de 100. A cinza é o resíduo composto de óxidos minerais obtidos ao final, após a combustão completa do carvão vegetal.

Tabela 2. Referências normativas para os ensaios.

\begin{tabular}{ccc}
\hline Tipo de ensaio & Unidade & Referência normativa \\
\hline $\begin{array}{c}\text { Poder calorífico superior (PCS) } \\
\text { Teor de cinzas (TCZ) }\end{array}$ & $\mathrm{kcal} \mathrm{kg}^{-1}$ & ABNT NBR 8633/1984 \\
$\begin{array}{c}\text { Teor de materiais voláteis (TMV) } \\
\text { Teor de carbono fixo (TCF) }\end{array}$ & $\%$ & ABNT NBR 8112/1986 \\
Umidade (U) & & \\
$\begin{array}{c}\text { Avaliação da embalagem e de } \\
\text { informações ao consumidor }\end{array}$ & $\begin{array}{c}\text { Aspectos } \\
\text { visuais }\end{array}$ & Resolução no 40, (São Paulo, 2015) \\
\hline
\end{tabular}


A avaliação de características das embalagens do carvão vegetal e das informações ao consumidor, contidas nos seus rótulos, foram realizadas visualmente e comparativamente, com base na Resolução no 40 da Secretaria de Agricultura e Abastecimento do Estado.

A análise estatística dos dados originais foi processada no software Excel (MICROSOFT, 2015). Em particular, buscou-se avaliar a variabilidade dos dados e o comportamento dos valores médios obtidos para o carvão vegetal, com a análise descritiva das amostras e determinação de parâmetros de tendência

\section{RESULTADOS E DISCUSSÃO}

$\mathrm{Na}$ Tabela 3 estão apresentados os resultados das análises realizadas nas cinco amostras de carvão vegetal. Em geral, os resultados apresentaram baixos central e de dispersão, além do coeficiente de variação de Pearson, que representa o desvio-padrão expresso como porcentagem da média.

$\mathrm{O}$ experimento foi instalado segundo um delineamento inteiramente casualizado, com cinco amostras e três repetições, totalizando 15 unidades amostrais. Para a comparação entre as médias realizou-se análise de variância (teste F) e, quando estabelecidas diferenças significativas, os tratamentos foram comparados entre si, por meio do teste de Tukey, a 5\% de significância.

coeficientes de variação de Pearson (CV), indicando bom controle experimental e boa precisão dos dados.

Tabela 3. Valores médios dos teores de umidade, materiais voláteis, carbono fixo, cinzas e poder calorífico superior do carvão vegetal.

\begin{tabular}{ccccccc}
\hline \multirow{2}{*}{ Amostra } & $\begin{array}{c}\text { Estatística } \\
\text { descritiva }\end{array}$ & $\begin{array}{c}\mathrm{U} \\
(\%)\end{array}$ & $\begin{array}{c}\text { TMV } \\
(\%)\end{array}$ & $\begin{array}{c}\text { TCF } \\
(\%)\end{array}$ & $\begin{array}{c}\text { TCZ } \\
(\%)\end{array}$ & $\begin{array}{c}\text { PCS } \\
\left(\mathrm{kcal} \mathrm{kg}^{-1}\right)\end{array}$ \\
\hline \multirow{3}{*}{1} & Média & $5,19 \mathrm{~d}$ & $15,53 \mathrm{c}$ & $83,67 \mathrm{~b}$ & $0,80 \mathrm{c}$ & $7.168 \mathrm{a}$ \\
& DP & 0,25 & 1,03 & 0,94 & 0,05 & 14,50 \\
& CV & 4,88 & 6,61 & 1,13 & 5,61 & 0,20 \\
2 & Média & $7,60 \mathrm{~b}$ & $12,72 \mathrm{~d}$ & $85,86 \mathrm{a}$ & $1,42 \mathrm{~b}$ & $7.070 \mathrm{~b}$ \\
& DP & 0,56 & 0,69 & 1,10 & 0,28 & 28,00 \\
& CV & 7,33 & 5,42 & 1,28 & 19,38 & 0,40 \\
3 & Média & $6,54 \mathrm{c}$ & $23,15 \mathrm{a}$ & $75,86 \mathrm{~d}$ & $0,99 \mathrm{c}$ & $6.815 \mathrm{c}$ \\
& DP & 0,37 & 0,64 & 0,86 & 0,08 & 35,00 \\
& CV & 5,61 & 2,76 & 1,13 & 8,02 & 0,51 \\
4 & Média & $6,08 \mathrm{c}$ & $14,88 \mathrm{c}$ & $83,80 \mathrm{~b}$ & $1,32 \mathrm{~b}$ & $6.838 \mathrm{c}$ \\
& DP & 0,18 & 1,40 & 2,50 & 0,10 & 82,50 \\
& CV & 2,88 & 9,44 & 2,99 & 7,91 & 1,21 \\
5 & Média & $10,54 \mathrm{a}$ & $17,48 \mathrm{~b}$ & $80,79 \mathrm{c}$ & $1,73 \mathrm{a}$ & $6.375 \mathrm{~d}$ \\
& DP & 0,84 & 0,89 & 0,88 & 0,05 & 75,00 \\
& CV & 8,0 & 5,12 & 1,08 & 2,86 & 1,18 \\
\hline
\end{tabular}

U=umidade; TMV=teor de materiais voláteis; TCF=teor de carbono fixo; TCZ=teor de cinzas; $\mathrm{PCS}=$ poder calorífico superior; $\mathrm{DP}=$ desvio padrão; $\mathrm{CV}=$ coeficiente de variação de Pearson; Médias seguidas da mesma letra, na coluna, não diferem entre si, a $5 \%$ de significância, pelo teste de Tukey.

Quanto à umidade, é possível verificar que as amostras apresentaram diferenças estatísticas ao nível de 5\% de significância, exceto para o carvão vegetal 3 e 4. Na prática, essas diferenças na umidade podem influenciar negativamente 
o poder calorífico superior dos biocombustíveis. Isso pode ter ocorrido no material 5, por exemplo, que apresentou elevada umidade e menor PCS entre todas as amostras. ROSA et al. (2012) mencionaram que o carvão vegetal para ser considerado de boa qualidade para o uso doméstico, deve conter umidade menor do que $5,0 \%$. Entretanto, as cinco amostras apresentaram umidades superiores aos da literatura de referência, apresentada na Tabela 4. Além disso, a umidade das amostras na faixa de $5,19-10,54 \%$, não atende aos parâmetros de qualidade da Resolução no 40 (SÃO PAULO, 2015), que estabelece umidade máxima de 5,0\%. ROSA et al. (2012), analisaram 12 amostras comerciais de carvão vegetal no Estado de Minas Gerais e também concluíram que nenhuma delas cumpriam este item de qualidade. Embora existam padrões mínimos de referência estabelecidos na Resolução normativa, os produtores de carvão vegetal não se empenham em atendê-los, lesando o consumidor final do produto.

Quanto aos materiais voláteis, observou-se diferenças estatísticas entre as amostras, com exceção da 1 e 4 . Somente as amostras 3 e 5 apresentaram valores médios coerentes com a literatura de referência, para as outras amostras, os resultados foram inferiores aos apresentados na Tabela 4.

Tabela 4. Valores de referência para a análise imediata e poder calorífico superior do carvão vegetal de algumas espécies de Eucalyptus.

\begin{tabular}{ccccccc}
\hline $\begin{array}{c}\text { U } \\
(\%)\end{array}$ & $\begin{array}{c}\text { TMV } \\
(\boldsymbol{\%})\end{array}$ & $\begin{array}{c}\text { TCZ } \\
(\boldsymbol{\%})\end{array}$ & $\begin{array}{c}\text { TCF } \\
(\boldsymbol{\%})\end{array}$ & $\begin{array}{c}\text { PCS } \\
\left(\mathbf{K c a l ~ k g}^{-1}\right)\end{array}$ & Espécie & Referência \\
\hline 3,0 & 24,5 & 0,80 & 71,4 & 7.367 & Eucalyptus benthamii & (LIMA et al., 2012) \\
4,2 & 23,6 & 0,68 & 75,5 & 7.432 & Eucalyptus sp. & (ROSA et al., 2012) \\
4,3 & 21,3 & 1,65 & 75,3 & 7.436 & Eucalyptus sp. & (ROSA et al., 2012) \\
- & 26,1 & 0,67 & 73,3 & 7.086 & Eucalyptus urophylla & (REIS et al., 2012) \\
- & 24,1 & 0,61 & 75,3 & 7.384 & Eucalyptus sp. & (CASTRO et al., 2013) \\
5,0 & 21,4 & 1,0 & 77,7 & 7.118 & Eucalyptus sp. & (JÚNIOR et al., 2015) \\
\hline
\end{tabular}

U=umidade; TMV=teor de materiais voláteis; TCF=teor de carbono fixo; TCZ=teor de cinzas; $\mathrm{PCS}=$ poder calorífico superior.

De acordo com OLIVEIRA et al. (2012), para uso doméstico, altos teores de materiais voláteis estão associados à geração de fumaça, baixa eficiência energética além de acarretar maior consumo de carvão vegetal. Sendo assim, nesse quesito, as amostras 2 e 4 apresentaram as melhores características para uso doméstico. E, por fim, todas as amostras atenderam os critérios estabelecidos na normativa, que sugerem valores menores que $25,5 \%$ como referencial para o carvão vegetal "Qualidade São Paulo".

Para o carbono fixo, nota-se que as amostras apresentaram ampla faixa de valores entre $75,86-85,86 \%$ e, em geral, diferenças significativas entre as médias foram confirmadas pelo teste de Tukey.
Somente a amostra 3 apresentou valores médios coerentes com a literatura referencial da Tabela 4. No entanto, de acordo com os critérios estabelecidos na Resolução no 40 (SÃO PAULO, 2015), de teor médio de carbono fixo maior que $73 \%$, todas as amostras desse estudo atenderam esse quesito de qualidade. Ademais, de acordo com SANTOS et al. (2011), maiores teores de carbono fixo estão associados a maiores valores de PCS, representando mais energia disponível na utilização doméstica desse carvão vegetal. Alguns autores (SOUZA et al., 2016; CARNEIRO et al., 2014) explicam que, na produção do carvão vegetal, o carbono é convertido em carbono fixo, sendo esse o principal responsável pela energia estocada no biocombustível. Assim, as amostras 2 e 
4 seriam as mais qualificadas, nesse quesito de qualidade, para uso doméstico.

Quanto às cinzas, os resultados médios das amostras de carvão vegetal desse estudo, na faixa de 0,80-1,73\%, apresentaram valores semelhantes à literatura de referência, entre 0,61-1,65\% (Tabela 4). Sabe-se que as cinzas possuem correlação negativa com o poder calorífico, ou seja, quanto maiores os teores de cinzas menores serão o poder calorífico do combustível, porque esses elementos inorgânicos não participam do processo de combustão (Costa et al., 2014). Sendo assim, as amostras 1 e 3 apresentaram resultados compatíveis com o carvão vegetal "Qualidade São Paulo", descrito na Resolução no 40. Mas, o carvão vegetal 5, com teores de cinzas superiores a $1,5 \%$, não atendeu esta referência normativa. GARCIA et al. (2013) relatam que a madeira, em geral, possui baixos teores de cinzas e que valores elevados como encontrados nas amostras 2, 4 e 5, podem surgir de fontes externas como impurezas adquiridas no transporte ou no processamento mecânico da matéria-prima.

$\mathrm{Na}$ Tabela 3 estão apresentados os valores médios do poder calorífico superior das cinco amostras de carvão vegetal. Elas apresentaram diferenças estatísticas em nível de 5\% de significância, portanto, os diferentes PCS influenciam na eficiência térmica do produto e na qualidade final do carvão vegetal. Os valores, na faixa de 6.375-7.168 kcal $\mathrm{kg}^{-1}$, apresentaram discrepâncias, em relação aos referenciais da literatura, apresentados na Tabela 4, de 7.086-7.436 kcal kg-1, coincidindo apenas a amostra 1. Portanto, nesse parâmetro de qualidade, o carvão vegetal 1 se mostrou com características mais adequadas para uso doméstico, pois liberará maior quantidade de energia.

ROSA et al. (2012) destacaram a relação inversa da umidade com o PCS, que ocorre porque a água absorve parte da energia liberada do carvão vegetal na vaporização. Então, quanto maior a umidade mais massa o carvão vegetal irá perder para evaporar a água contida na sua estrutura, diminuindo seu poder energético. Por causa disso, a amostra 5, com elevada umidade e baixo poder calorífico superior, pode ser considerado como um carvão vegetal de baixa qualidade para uso doméstico. Além disso, no uso prático do combustível sólido, o poder calorífico superior é um indicador de qualidade imprescindível nas especificações normativas, a fim de garantir efetivamente referencial de qualidade aos produtos.

Avaliando as embalagens, em relação às informações pertinentes ao produto estabelecidas na Resolução no 40 (SÃO PAULO, 2015), verifica-se que todas as amostras apresentaram o número do cadastro nacional da pessoa jurídica (CNPJ), o número do registro no órgão ambiental (CETESB) e federal (IBAMA). Os produtos se encontravam em embalagens de papel reciclável, como determina a normativa. Porém, as amostras 2, 4 e 5 não apresentaram o endereço da empresa, sendo que a amostra 4 não constava nem sequer o nome da empresa. Portanto, é possível inferir que essas empresas não cumprem os padrões mínimos quanto aos rótulos dos produtos exigidos na normativa.

Diante disso e com base no Código de Defesa do Consumidor (BRASIL, 1990), que assegura que informação é um direito do consumidor e deve ser prestada de forma clara e objetiva para que o consumidor saiba exatamente o que está adquirindo, recomenda-se que as exigências mínimas de qualidade da Resolução no 40 sejam obrigatoriamente impressas na embalagem, conforme sugestão na Tabela 5. 
Tabela 5. Sugestão de rótulo para impressão nas embalagens de carvão vegetal

\begin{tabular}{cc}
\hline \multicolumn{2}{c}{ Resolução no 40, SAA de 2015 } \\
Carvão Vegetal “Qualidade São Paulo" \\
Madeira de reflorestamento: Eucalyptus \\
\hline Umidade & $<5,0 \%$ \\
Carbono Fixo & $>73,0 \%$ \\
Materiais Voláteis & $<23,5 \%$ \\
Cinzas & $<1,5 \%$ \\
Poder Calorífico Superior & $>7.000 \mathrm{kcal} \mathrm{kg}^{-1}$ \\
\hline
\end{tabular}

Nesse novo rótulo, além das informações já obrigatórias como nome da empresa, CNPJ, tipo de matéria-prima, acrescenta-se também todas as informações de qualidade como umidade, carbono fixo, materiais voláteis e cinzas, além do poder calorífico superior, que representa informação indispensável para a caracterização de qualidade energética de um biocombustível.

A Tabela 6 apresenta um resumo dos padrões de qualidade da Resolução no 40 (SÃO PAULO, 2015) em relação as características dos carvões vegetais como umidade, materiais voláteis, cinzas, carbono fixo e informações impressas nos rótulos das embalagens. As amostras foram avaliadas se estavam (sim) ou não em conformidade com as referências mínimas de qualidade.

Esses resultados, compilados, revelam que dos 25 parâmetros avaliados, em $36 \%$ deles, o carvão vegetal não atendeu a referência de qualidade mínima determinada pela Resolução no 40. O carvão vegetal 5 não atendeu três quesitos da normativa e apresentou-se como o de menor qualidade, enquanto o carvão vegetal 1, pode ser classificado, comparativamente, como o produto com as melhoras características para uso doméstico.

Tabela 6. Resumo comparativo do atendimento as exigências normativas da Resolução no 40.

\begin{tabular}{cccccc}
\hline Carvão vegetal & UMI & TMV & TCZ & TCF & EMBALAGEM \\
\hline Amostra 1 & Não & Sim & Sim & Sim & Sim \\
Amostra 2 & Não & Sim & Sim & Sim & Não \\
Amostra 3 & Não & Sim & Sim & Sim & Sim \\
Amostra 4 & Não & Sim & Sim & Sim & Não \\
Amostra 5 & Não & Sim & Não & Sim & Não \\
\hline
\end{tabular}

Portanto, os consumidores de carvão vegetal estão sendo prejudicados duplamente: por comprarem produtos que não atendem as referências mínimas de

\section{CONCLUSÕES}

Todas as amostras de carvão vegetal apresentaram elevados teores de umidade e não atenderam aos critérios de qualidade especificados na normativa;

As amostras 2, 4 e 5 não informaram, nos rótulos das embalagens, caraterísticas qualidade; e por não terem informações claras e objetivas nas embalagens dos produtos, como determina o Código do Consumidor.

básicas do carvão vegetal como sugere a normativa;

A amostra 5 apresentou elevados teores de cinzas que ultrapassam os limites determinados pela resolução normativa. 


\section{REFERÊNCIAS}

ASSOCIAÇÃO BRASILEIRA DE NORMAS TÉCNICAS - ABNT. NBR 8112: carvão vegetal - Análise Imediata. Rio de Janeiro; 1986.

ASSOCIAÇÃO BRASILEIRA DE NORMAS TÉCNICAS - ABNT. NBR 8633: carvão vegetal- determinação do poder calorífico. Rio de Janeiro; 1984.

BRASIL - BEN: Balanço energético nacional 2016 ano base 2015. Empresa de Pesquisa Energética. Brasília; 2016.

BRASIL - Ministério da Justiça: Código de defesa e proteção do consumidor. Lei 8.078, de 11 de setembro de 1990 .

CARNEIRO, A.C.O.; CASTRO, A.F.N.M.; CASTRO, R.V.O.; SANTOS, R.C.S.; FERREIRA, L.P.; DAMÁSIO, R.A.P.; VITAL, B.R. Potencial energético da madeira de Eucalyptus sp. em função da idade e de diferentes materiais genéticos. Revista Árvore, v. 38 (2): 375-381, 2014.

CASTRO, A.F.N.M.; CASTRO, R.V.O.C.; CARNEIRO, A.C.O.C.; LIMA, J.E.L.; SANTOS, R.C.S.; PEREIRA, B.L.C.P.; ALVES, I.C.N. Análise multivariada para seleção de clones de eucalipto destinados à produção de carvão vegetal. Pesquisa Agropecuária Brasileira, v. 48 (6): 627635, 2013.

COSTA, T.G.C.; BIANCHI, M.L.; PROTÁSIO, T.P.; TRUGILHO, P.F.; PEREIRA, A.J. Qualidade da madeira de cinco espécies de ocorrência no cerrado para produção de carvão vegetal. Cerne, v. 20 (1): 37-45, 2014.

DIAS JÚNIOR, A.F.; ANDRADE, C.R.; BRITO, J.O.; MILAN, M. Desdobramento da função qualidade (QFD) na avaliação da qualidade do carvão vegetal utilizado para cocção de alimentos. Floresta e Ambiente, v. 22 (2): 262-270, 2015.

GARCIA, D. P.; CARASCHI, J. C.; VENTORIM, G. Caracterização energética de pellets de madeira. Revista da Madeira, v. 24 (135): 14-16, 2013.
JUNG，S.J.; KIM， S.H.; CHUNG，I.M. Comparison of lignin, cellulose, and hemicellulose contents for biofuels utilization among 4 types of lignocellulosic crops. Biomass and Bioenergy, v. 83 (1): 322-327, 2015.

LANA, A.Q.; SALLES, T.T.; CARNEIRO, A.C.O.C.; CARDOSO, M.T.; TEIXEIRA, R.U. Comparison of procedures for immediate chemical analysis of charcoal. Revista Árvore, v. 40 (2): 371-376, 2016.

LIMA, E.A.; SILVA, H.D.; TUSSOLINI, E.L. Potencial do Eucalyptus benthamii para produção de carvão em fornos convencionais. Embrapa: Comunicado Técnico 305. Colombo, 2012.

MICROSOFT. Office 365 - Software estatístico Excel versão 2013. Disponível em: <https://products.office.com/pt-br/>. Acesso em: 12 out. 2015.

OLIVEIRA, A.C.; ROCHA, M.F.V.; PEREIRA, B.L.C.; CARNEIRO, A.C.O.; CARVALHO, A.M.M.L.; VITAL, B.R. Variação nas características da madeira e do carvão de um clone de Eucalyptus grandis W. Hill ex Maiden x Eucalyptus urophylla. Floresta, v. 42 (1): 56-68, 2012.

SÃO PAULO: Secretaria de Agricultura e Abastecimento. Resolução no 40 SAA, de 14 de dezembro de 2015.

REIS, A.A.; MELO, I.C.N.A.; PROTÁSIO, T.P.; TRUGILHO, P.F.; CARNEIRO, A.C.O. Efeito de local e espaçamento na qualidade do carvão vegetal de um clone de Eucalyptus urophylla S. T. Blake. Floresta e Ambiente, v. 19 (4): 497-505, 2012.

ROSA, R.A.; ARANTES, M.D.C.; PAES, J.B.; ANDRADE, W.S.P.; MOULIN, J.C. Qualidade do carvão vegetal para o consumo doméstico. Journal of Biotechnology and Biodiversity, v. 3 (2): 41-48, 2012.

SANTOS, R.C.; CARNEIRO, A.C.O.; CASTRO, A.F.M.; CASTRO, R.V.O.; 
BIANCHE, J.J.; SOUZA, M.M.; CARDOSO, M.T. Correlações entre os parâmetros de qualidade da madeira e do carvão vegetal de clones de eucalipto. Scientia Forestalis, v. 39 (90): 221-230, 2011.

SOUZA, N.D.; AMODEI, J.B.; XAVIER, C.N.; DIAS JÚNIOR, A.F.; CARVALHO, A.M. Estudo de caso de uma planta de carbonização: avaliação de características e qualidade do carvão vegetal visando uso siderúrgico. Floresta e Ambiente, v. 23 (2): 270-277, 2016. 